\title{
The Effects of GeoGebra on Third Grade Primary Students' Academic Achievement in Fractions
}

\author{
Mehmet Bulut, Hanife Ünlütürk Akçakın \& Gürcan Kaya \\ Gazi University, Gazi Faculty of Education, TURKEY \\ Veysel Akçakın \\ Uşak University, Education Faculty, TURKEY
}

•Received 12 April 2015•Revised 22 August $2015 \bullet$ Accepted 17 December 2015

\begin{abstract}
The aim of this study is to examine the effects of GeoGebra on third grade primary students' academic achievement in fractions concept. This study was conducted with 40 students in two intact classes in Ankara. One of the classes was randomly selected as an experimental group and other for control group. There were 19 students in the experimental group, while 21 students in control group. The matching- only posttestonly control group quasi-experimental design was employed. As a pretest, student's first term mathematics scores were used. Data were collected with post-test about fractions. The post-test consisted of 22 short ended questions. Thanks to the scores weren't violated the normality, independent $t$ test was employed. The findings of the study showed that there were significant differences in favor of the experimental group. According to findings of this study, it was recommended that GeoGebra supporting teaching methods can be used on teaching fractions in third grade.
\end{abstract}

Keywords: third grade, fractions, geogebra, achievement

\section{INTRODUCTION}

Approaches to teaching and learning of mathematics have been evolving in relation with technology. Several dynamic software tools geared towards towards mathematics education provide visually-rich contexts that enable students comprehend concepts in a meaningful way. Providing students with the representations of concepts and the interrelations among the representations is part of meaningful learning (Suh, Moyer \& Hu 2005; Van de Walle, Karp \& Bay-Williams, 2012). Similarly, National Council of Teachers of Mathematics [NCTM] (2000) highlights the importance of the use of multiple representations in improving children's mathematical thinking and reasoning. Dynamic mathematical software programs enable students make connections among the representations easily and meaningfully, which would be quite difficult to reach, if not impossible at all, without such dynamic tools. Low-achieving students are usually less successful in visualizing

Correspondence: Veysel Akçakın, Uşak University, Education Faculty, TURKEY

E-mail: veyselakcakin@gmail.com

doi: $10.29333 /$ iejme/338 
mathematical concepts compared to their high-achieving counterparts. Therefore, visual representation of mathematical concepts is much more crucial for lowachieving individuals (Moyer-Packenham, Ulmer \& Anderson, 2012). From this point of view, dynamic mathematics software appears to be advantageous for teachers to reduce achievement differences among students. There exist studies in the literature involving dynamic mathematics software in mathematics education where a substantial increase in student success was observed (Gutiérrez \& Boero, 2006; Martín-Caraballo \& Tenorio-Villalón, 2015).

Fractions are introduced to children in the primary school following the four operations, which is one of the fundamental subjects that they will be using throughout their school years and beyond. Generally, introduction of fractions is regarded as the turning point where most students encounter learning difficulties in mathematics (Clements, Sarama \& DiBiase, 2004). Learners generally utilize intuitive learning methods in learning numbers and four operations, and such learning methods do not apply to learning fractions, which causes students regard fractions as a difficult subject (McNamara \& Shaughnessy, 2010). In line with this conceptualization, mathematics education focusing on integers and compatible with the elementary topics may not be successful carrying students over to fractions and rational numbers (Clements, et al., 2004) because students are prone to generalize the knowledge and experience they learned during the topic of integers to fractions, which has a quite different structure than integers (Van de Walle et al., 2012). In addition, teaching fractions with no emphasis on conceptual learning (Lee \& Boyadzhiev, 2013; Pesen, 2007; Van de Walle et al., 2012), teaching fractions only as an operational knowledge (Lee \& Boyadzhiev, 2013), the fact that the concept of fraction has multiple meanings, and children's misconception of taking nominators and denominators as separate numerical values yield additional difficulties in children's learning of fractions (Van de Walle et al., 2012). Therefore, in teaching fractions, focusing on the 'feeling' of numbers and the meaning of fractions, and presenting similarities and differences between integers and fractions with the help of unorthodox visual models and content, which are usually not part of traditional teaching methods, are warranted (Van de Walle et al., 2012).

The books used in the current teaching contexts and the visual models in the curriculum are 2-dimensional, fixed, and static, and they are usually used representing only the concepts of half and quarter (Newstead \& Murray 1998; Goodwin, 2008). With the use of innovative dynamic models in teaching fractions in the primary school, students' comprehension of the concept of fractions will be easier and more meaningful (Goodwin, 2008). In this context, dynamic mathematics software tools are the best options in designing visual and dynamic models in teaching fractions. There exist studies in the literature regarding teaching fractions in Turkish schools in Grade 6 (Acar, 2010; Demirdöğen, 2007; Mısral, 2009), Grade 5 (Akın, 2009; Erdağ, 2011; Yurtsever, 2012), Grade 4 (Pilli, 2008; Sözer, 2006; Yumuşak, 2014), and both Grades 4 and 5 (Kayhan, 2010; Yazgan, 2007). However, to the best of our knowledge, there exists no study regarding teaching fractions in Grade 3 in Turkish schools. Moreover, only one of these studies, Pilli (2008), examined the effects of technology on teaching fractions. Pilli reported that the use of technology improved learners' success in learning fractions. Fractions are introduced first in Grade 3. However, there are few studies examining the relationship between technologies and teaching fractions, and there is no study on this topic involving Grade 3 students. Therefore, the aim of the present study was to observe the effects of GeoGebra-supported mathematics education on Grade 3 students' learning rate of fractions. 
Table 1 The design of the study

\begin{tabular}{llll}
\hline Experimental Group & $M$ & $X$ & $O$ \\
Control Group & $M$ & $C$ & $O$ \\
\hline
\end{tabular}

M: Matching X: Experimental Process C: Normal Process $\quad$ O: Post Test

\section{METHOD}

This study was conducted with 40 students in two intact classes in Ankara (Turkey) from an elementary state school. One of the classes was randomly selected as an experimental group and other for control group. There were 19 students in the experimental group, while 21 students in control group. This research was carried out in the second semester of 2013-2014 academic year. The matching-only posttest-only control group design was used in this study. After selecting control and experimental groups, the students were matched according to their first term mathematics scores.

The study was carried out for total 10 hours. During the process of preparing activities and post-test questions Turkish national elementary school curriculum was considered and 6 activities were prepared. Dynamic representational models, which differ from the concrete, static representations commonly found in textbooks, were used in the activities. The activities were revised by consulting experts. In the experimental group dynamic oriented activities were used by using constructive approach. In the control group normal teaching sequence in the curriculum was followed. The relevant data were collected with 22 short answered questions. Some of the questions contain sub questions. So there were 48 short answered questions in the post-test. It was obtained a Cronbach's alpha of .955, indicating a good level of reliability level. The test was prepared with three academicians according to educational aims about fractions in the third grade Turkish national elementary mathematics curriculum. During the process of preparing the questions necessary revisions were made on the questions through consultation. The researchers separated questions into 3 categories by considering the grade level of students. The categories were: 1) easy questions 2) difficult question 3) higher level thinking question. The answers of the students' post-test papers were checked with a rubric by researchers. In the rubric, wrong answers were given 0 point and the others were given the same point as their category. The overall score can be taken from the post test is 80 . After checking all the post tests, the scores of the students were converted to hundred scale by multiplying the total scores by 1.25 . The scores obtained from the tests were analyzed using mean, standard deviation, $t$-test and ANCOVA at .05 level of significance.

\section{Findings}

To test the hypothesis some test statistics are being used. It is very important to check the assumptions before deciding which statistical test is appropriate. There are two kinds of statistics method that you can do while testing hypothesis: Parametric and non-parametric. Most parametric tests have two major assumptions that should be met for the test to be accurate. The data collected from the sample should be normally distributed and the homogeneity of variances should be equal. But non-parametric tests have no such assumptions. Hence before testing hypothesis it was checked normality of data and homogeneity of variances.

\section{Descriptive Statistics of Study Group}

Table 2 shows descriptive statistics for experimental and control groups. 
Table 2 Descriptive statistics for groups

\begin{tabular}{lcc}
\hline Groups & frequency $(f)$ & percent (\%) \\
\hline Experimental & 19 & 47.5 \\
Control & 21 & 52.5 \\
\hline
\end{tabular}

As seen in Table 2, 19 students enrolled in experimental group while 21 students in control group. In the total 40 students enrolled in this study. Table 3 shows distribution of study group with respect to gender.

Table 3 Distribution of study group with respect to gender

\begin{tabular}{|c|c|c|c|c|}
\hline \multirow{3}{*}{ Groups } & \multicolumn{4}{|c|}{ Gender } \\
\hline & \multicolumn{2}{|c|}{ Girls } & \multicolumn{2}{|c|}{ Boys } \\
\hline & $f$ & $\%$ & $f$ & $\%$ \\
\hline Experimental & 10 & 52.6 & 9 & 47.4 \\
\hline Control & 13 & 62 & 8 & 38 \\
\hline
\end{tabular}

\section{Normality of Data}

To test the normality of the students' first term mathematics scores, KolmogorovSmirnov $Z$ test was used. Table 4 shows normality of first term mathematics scores result and Table 5 shows normality of fractions achievement scores result.

Table 4 Normality of first term mathematics scores

\begin{tabular}{lccccc}
\hline Groups & $\begin{array}{c}\text { Kolmogorov- } \\
\text { Smirnov } \boldsymbol{Z}\end{array}$ & $\boldsymbol{p}$ & $\boldsymbol{d} \boldsymbol{f}$ & Mean & Variance \\
\hline Experimental & .178 & .113 & 19 & 74.55 & 141.58 \\
Control & .120 & $.200^{*}$ & 21 & 72.67 & 123.55 \\
\hline
\end{tabular}

${ }^{*}$ This is a lower bound of the true significance

As seen in Table 4, experimental group first term mathematics scores, $D(19)=0.178 p>.05$ and Control group first term mathematics scores $D(21)=0.120$, $p>0.05$, were significantly normal.

Table 5 Normality of fractions academic achievement scores

\begin{tabular}{lccccc}
\hline Groups & $\begin{array}{c}\text { Kolmogorov- } \\
\text { Smirnov Z }\end{array}$ & $\boldsymbol{p}$ & $\boldsymbol{d f}$ & Mean & Variance \\
\hline Experimental & .119 & $.200^{*}$ & 19 & 55.79 & 850.037 \\
Control & .139 & $.200^{*}$ & 21 & 34.4 & 433.065 \\
\hline
\end{tabular}

${ }^{*}$ This is a lower bound of the true significance

As seen in Table 5, experimental group fractions achievement scores, $D(19)=0.119$ p $>.05$ and Control group first term mathematics scores $D(21)=0.139$, $p>0.05$, were significantly normal.

\section{Homogeneity of Variance}

To test the homogeneity of the students' first term mathematics scores and fractions academic achievement scores, the Levene test was used. Table 6 shows homogeneity of first term mathematics scores and fractions academic achievement scores.

As seen in Table 6, the variances of the first term mathematics scores were equal for experimental and control groups $F(1,38)=.195 p>.05$ and the variances of fractions academic achievement were also equal for experimental and control groups $F(1,38)=3.081 p>.05$. 
Table 6 Homogeneity of first term mathematics (FTM) scores and fractions academic achievement (FAA) scores

\begin{tabular}{lcccc}
\hline Tests & $\begin{array}{c}\text { Levene statistic } \\
\text { (Based on Mean) }\end{array}$ & $\boldsymbol{d f}_{\mathbf{1}}$ & $\boldsymbol{d f}_{\mathbf{2}}$ & $\boldsymbol{p}$ \\
\hline FTM & 0.195 & 1 & 38 & .662 \\
FAA & 3.081 & 1 & 38 & .087 \\
\hline${ }^{*} p<.05$ & & & &
\end{tabular}

Table 7 Means, standard deviations and t value for first term mathematics scores

\begin{tabular}{llcccc}
\hline Groups & $\boldsymbol{N}$ & Mean & $\boldsymbol{S D}$ & $\boldsymbol{t}$ & $\boldsymbol{p}$ \\
\hline Experimental & 19 & 74.55 & 11.90 & -.518 & .607 \\
Control & 21 & 72.67 & 11.12 & & \\
\hline${ }^{*} p<.05$ & & & & &
\end{tabular}

Table 8. Means, standard deviations and $t$ value for fractions academic achievement scores of the study groups

\begin{tabular}{lccccc}
\hline Groups & $\boldsymbol{N}$ & Mean & $\boldsymbol{S D}$ & $\boldsymbol{t}$ & $\boldsymbol{p}$ \\
\hline Experimental & 19 & 55.79 & 29.16 & \multirow{2}{*}{$-2.69^{*}$} & .011 \\
Control & 21 & 34.40 & 20.81 & &
\end{tabular}

A non-significant Kolmogorov-Smirnov $Z$ test and homogeneity of variance revealed that normality assumptions of independent $t$ test were met. Before the experimental interventions, independent $t$ test was used to check the groups' equality. Table 7 shows independent $t$ test results.

An independent-samples $t$ test was conducted to compare the first term mathematics scores for experimental and control groups. There was no significant difference between the first term mathematics scores of experimental $(M=74.55$, $S D=11.9)$ and control group $(M=72.67, S D=11.12) ; t(38)=-.518, p=.607$. The magnitude of the differences in the means (mean difference $=1.88$ ) was very small (eta squared $=.007$ ).

After the experiment, fractions academic achievement test was applied to two groups. Table 8 shows independent $t$ test results.

An independent-samples $t$ test was conducted to compare the fractions academic achievement scores for experimental and control groups. There was significant difference in favor of the experimental $(M=55.79, S D=29.16)$ group than the control group $(M=34.4, S D=20.81) ; t(38)=-2.69, p=.011$. The magnitude of the differences in the means (mean difference $=21.39$ ) was very large (eta squared $=.16$ ).

To test covariate effect of the first term mathematics scores before the experiment to the fractions academic achievement scores, ANCOVA was applied. Preliminary analysis was conducted before the ANCOVA; normality, linearity, homogeneity of variances, homogeneity of regression slopes.

Normality assumptions of data are met and they are shown in Table 3 and Table 4. Another ANCOVA assumption is linear relationship between dependent variable and covariate. Figure 1 shows the linearity assumptions.

The square root of $R^{2}$ Linear gives the correlation of covariate and dependent variable. Thus the correlation was 0.583 , then the significance of this correlation can be found by calculating Pearson Correlation. Table 9 shows the correlation results.

As seen in Table 9, Covariate, first term mathematics scores, is positively related to the fractions academic achievement scores with a coefficient of $r=.583$ which is also significant at $p<.001$. To test the homogeneity of regression slopes, interaction between covariate and method were tested. Interaction is not significant $F(1,36)=.049, p=.827)$.

Levene's Test of Equality of Error Variances result $(F=3.498, p>.05)$ was met the assumptions of ANCOVA 


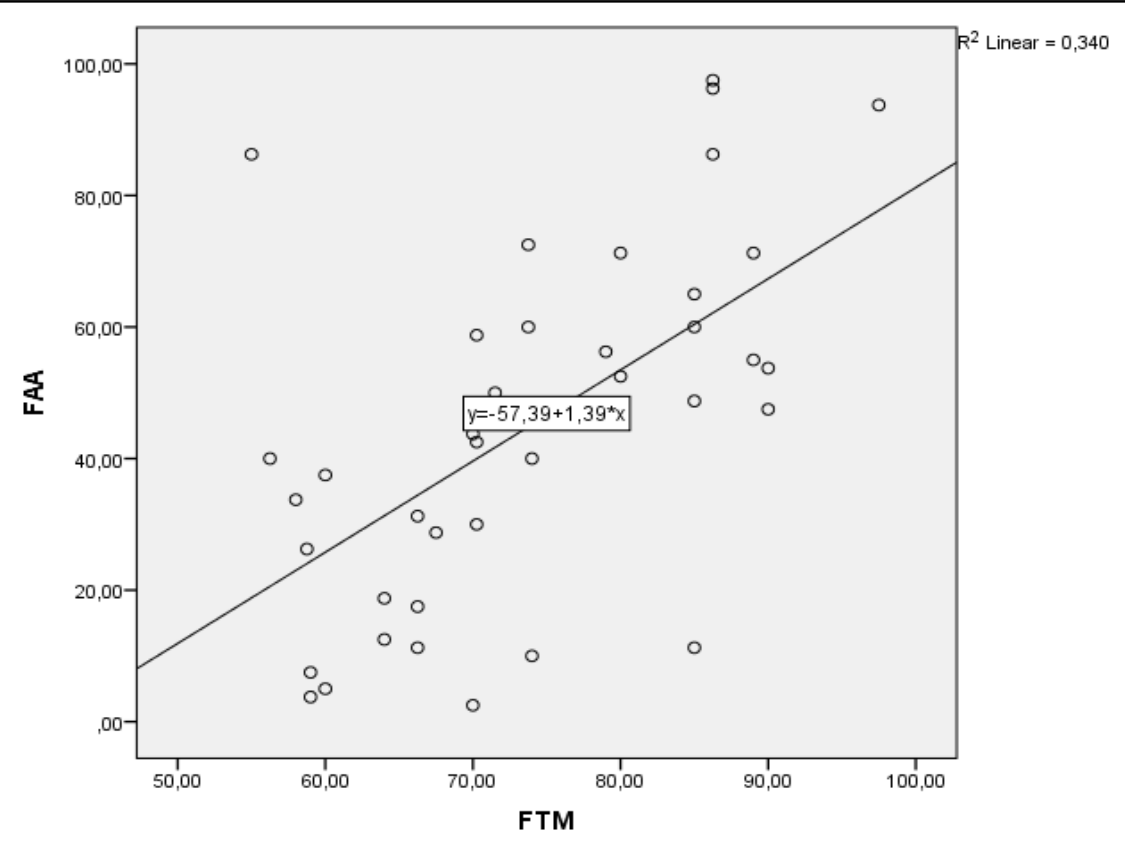

Figure 1. Linear relationship between dependent variable and covariate

Table 9 The correlation of covariate and dependent variable results.

\begin{tabular}{lcc}
\hline Variables & $\boldsymbol{r}$ & $\boldsymbol{p}$ \\
\hline FTM-FAA & $0.583^{* *}$ & .000 \\
\hline${ }^{* *} p<.0$
\end{tabular}

${ }^{* *} p<.01$

Table 10 Levene's Test of Equality of Error Variances result

\begin{tabular}{lccc}
\hline $\boldsymbol{F}$ & $\boldsymbol{d} \boldsymbol{f}_{\mathbf{1}}$ & $\boldsymbol{d} \boldsymbol{f}_{\mathbf{2}}$ & $\boldsymbol{p}$ \\
\hline 3.498 & 1 & 38 & .069 \\
\hline${ }^{*} p<.05$ & & &
\end{tabular}

Table 11 shows the adjusted means on the fractions academic achievement scores.

Table 11 Adjusted means on the fractions academic achievement scores

\begin{tabular}{lccc}
\hline Groups & $\boldsymbol{N}$ & Mean & adjusted means \\
\hline Experimental & 19 & 55.79 & 54.487 \\
Control & 21 & 34.40 & 35.583 \\
\hline
\end{tabular}

As seen in Table 11, Adjusted mean scores of the experimental group decrease 54.487 from 55.79, while the adjusted mean scores of control group increase 35.583 from 31.40. In the view of the adjusted scores, experimental group scores higher than control group as before.

Table 12 The ANCOVA results of post-test scores of groups

\begin{tabular}{llllllll}
\multicolumn{1}{c}{ Source } & $\begin{array}{c}\text { Type III Sum } \\
\text { of Squares }\end{array}$ & df & Mean Square & F & p & Partial $\eta^{2}$ \\
\hline Covariate & 8687.332 & 1 & 8687.332 & $21.043^{*}$ & .000 & .363 \\
Method & 3539.507 & 1 & 3539.507 & $8.574^{*}$ & .006 & .188 \\
Error & 15274.636 & 37 & 412.828 & & & \\
Total & 28523.594 & 39 & & & & \\
\hline
\end{tabular}

A one-way between-groups analysis of covariance was conducted to compare the effectiveness of two different teaching method (dynamic oriented activities, normal teaching sequence). The independent variable was the teaching method and the 
dependent variable was fractions academic achievement test administered after the intervention was completed. Participants' first term mathematics scores used as covariate in the analysis. Preliminary checks were conducted to ensure that there was no violation of the assumptions of normality, linearity, homogeneity of variances, homogeneity of regression slopes. As a result, the covariate, first term mathematics scores, was significantly related to the fractions academic achievement scores $F(1,37)=21.043, p<.05$, partial $\eta^{2}=.363$. There was also significant effect of method on levels of achievement after controlling for the effect of the first term mathematics scores, $F(1,37)=8.574, p<.05$, partial $\eta^{2}=.188$. The strength of the relationship between the method and achievement was very strong. Method explain $18.8 \%$ of the variance of the achievement.

\section{Conclusion and Discussion}

In this study, the effects of the using dynamic oriented activities using GeoGebra on achievement with the subject of fractions were analyzed. With respect to the first term mathematics scores, there was no significant difference between the experimental and control groups. Throughout the study, both groups' achievement was increased. However, post-test results show that there was a significant difference between the means of the students' post-test scores in favor of experimental group. These findings highlighted that, students in the experimental group which was used dynamic oriented activities with GeoGebra performed better than the control group which was used the traditional learning method. Hence, it can be considered that using multiple representations can enhance students' understanding of fraction concept. Based on the experimental group's significant post test results with comparison to control group, it can also be claimed that the teaching process of the experimental group, where multiple representations in a simultaneous and dynamic visual format were used, is effective for students on learning fractions. These findings are consistent with the results of the studies which found positive effects of dynamic oriented activities by using GeoGebra (Goodwin, 2008; Pitta-Pantazi, Gray \& Christou, 2004; Reimer \& Moyer, 2005; Suh, Moyer \& Heo, 2005; Thambi \& Eu, 2013). GeoGebra offers dynamic shifting between fraction models (e.g. area model, set model and number line model). Thus it can be asserted that students' learning of fraction concept can be enhanced by using different representational models with GeoGebra because using multiple representations are important for learning mathematics meaningfully. In addition, new standards and documents emphasize the use of by multiple representations in the development of mathematical thinking and reasoning (NCTM, 2000). According to finding of this study, it was recommended that GeoGebra supporting teaching methods can be used in third grade. As a result, this experimental research can promote researchers for further to examine the effectiveness of using dynamic multiple representations with GeoGebra on developing students' learning and understanding of other mathematical concepts.

\section{References}

Acar, N. (2010). The effect of fraction rulers on the addition and subtraction of fraction abilities of $6^{\text {th }}$ grade students of elementary school (Master's Thesis). Available from Council of Higher Education Thesis Center Database in Turkey. (Thesis No. 251433).

Akın, P. (2009). The effects of problem-based learning on students? Success in the teaching the topic fractions at the $5^{\text {th }}$ grade. (Master's Thesis). Available from Council of Higher Education Thesis Center Database in Turkey. (Thesis No. 241307). 
Clements, D. H., Sarama, J., \& DiBiase, A. M. (Eds.). (2004). Engaging young children in mathematics: Standards for early childhood mathematics education. Routledge.

Demirdöğen, N. (2007). The effect of realistic mathematics education method to the teaching fraction concept in $6^{\text {th }}$ classes of primary education. (Master's Thesis). Available from Council of Higher Education Thesis Center Database in Turkey. (Thesis No. 207129).

Erdağ, S. (2011). The effect of mathematics teaching supported by concepts cartoons decimal fractions on academic achievement and retention in $5^{\text {th }}$ grade classes of primary schools. (Master's Thesis). Available from Council of Higher Education Thesis Center Database in Turkey. (Thesis No. 296499).

Goodwin, K. (2008). The impact of interactive multimedia on kindergarten students' representations of fractions. Issues in Educational Research, 18(2), 103-117.

Gutiérrez, A., \& Boero, P. (Eds.). (2006). Handbook of research on the psychology of mathematics education: Past, present and future. Sense publishers.

Kayhan, H. C. (2010). Determining of primary school students? Mental models in the process of converting fractions each other. (Doctoral dissertation). Available from Council of Higher Education Thesis Center Database in Turkey. (Thesis No. 279658).

Lee, H.J. \& Boyadzhiev, I. (2013). Challenging Common Misconceptions of Fractions through GeoGebra. In R. McBride \& M. Searson (Eds.), Proceedings of Society for Information Technology \& Teacher Education International Conference 2013 (pp. 2893-2898). Chesapeake, VA: AACE.

Martín-Caraballo, A. M., \& Tenorio-Villalón, Á. F. (2015). Teaching Numerical Methods for Non-linear Equations with GeoGebra-Based Activities. Mathematics Education, 10(2), 53-65

McNamara, J., \& Shaughnessy, M. M. (2010). Beyond Pizzas \& Pies: 10 Essential Strategies for Supporting Fraction Sense, Grades 3-5. Math Solutions.

Misral, M. (2009). The effect of the education which is done by the different sub-constructs of fractions on the conceptual and operational knowledge levels of primary school $6^{\text {th }}$ grade students about adding subtraction and multiplication in fraction. (Master's Thesis). Available from Council of Higher Education Thesis Center Database in Turkey. (Thesis No. 237470).

Moyer-Packenham, P. S., Ulmer, L. A., \& Anderson, K. L. (2012). Examining Pictorial Models and Virtual Manipulatives for Third-Grade Fraction Instruction. Journal of Interactive Online Learning, 11(3),103-120.

Newstead, K. and Murray, H. (1998). Young students' constructions of fractions. In A. Olivier \& K. Newstead (Eds.), Proceedings of the Twenty-second International Conference for the Psychology of Mathematics Education: Vol. 3. (pp. 295-302). Stellenbosch, South Africa.

Pesen, C. (2007). Öğrencilerin kesirlerle ilgili kavram yanılgıları [Students' Misconceptions About Fractions]. Eğitim ve Bilim, 32(143), 79-88.

Pilli, O. (2008). The effects of computer-assisted instruction on the achievement, attitudes and retention of mathematics in 4th grade courses. (Doctoral dissertation). Available from Council of Higher Education Thesis Center Database in Turkey. (Thesis No. 27694).

Pitta-Pantazi, D., Gray, E., \& Christou, C. (2004). Elementary school students' mental representations of fractions. In Proceedings of the 28th annual conference of the International Group for the Psychology of Mathematics Education (Vol. 4, pp. 41-48).

Reimer, K., \& Moyer, P. S. (2005). Third-graders learn about fractions using virtual manipulatives: A classroom study. Journal of Computers in Mathematics and Science Teaching, 24(1), 5-25.

Sözer, N. (2006). The impact of drama method on fourth class students at mathematics in a primary school regarding success of students, their attitudes and learning retention. (Master's Thesis). Available from Council of Higher Education Thesis Center Database in Turkey. (Thesis No. 191047).

Suh, J., Moyer, P. S., \& Heo, H. (2005). Examining technology uses in the classroom: Developing fraction sense using virtual manipulative concept tutorials. Journal of Interactive Online Learning, 3(4), 1-21.

The National Council of Teachers of Mathematics [NCTM]. (2000). Principles and standards for school mathematics. Reston, VA: Author.

Thambi, N., \& Eu, L. K. (2013). Effect of Students' Achievement in Fractions using GeoGebra. SAINSAB. 16. 97-106. 
Van de Walle, J.A., Karp, K.S. \& Bay-Williams, J.M. (2010). Elementary and middle school mathematics teaching developmentally (Seventh Edition), USA: Pearson Publications.

Yazgan, Y. (2007). An experimental study on fraction understanding of children at the age of 10 and 11. (Doctoral dissertation). Available from Council of Higher Education Thesis Center Database in Turkey. (Thesis No. 220989).

Yumuşak, E. Y. (2014). The effects of game-supported mathematics learning unit of fractions of 4. grade achievement and permanence. (Master's Thesis). Available from Council of Higher Education Thesis Center Database in Turkey. (Thesis No. 351006).

Yurtsever, N.T. (2012). A study on fifth grade students' mistakes, difficulties and misconceptions regarding basic fractional concepts and operations. (Master's Thesis). Available from Council of Higher Education Thesis Center Database in Turkey. (Thesis No. 321086).

Note: This study was presented in the International Society of Educational Research [iSER] 2014 World Conference, Cappadocia, TURKEY 